\title{
Infrared and Raman spectroscopic characterization of the arsenate mineral ceruleite $\mathrm{Cu}_{2} \mathrm{Al}_{7}\left(\mathrm{AsO}_{4}\right)_{4}(\mathrm{OH})_{13} \cdot 11.5\left(\mathrm{H}_{2} \mathrm{O}\right)$
}

\author{
Ray L. Frost ${ }^{a}, *$, Andrés Lópes ${ }^{a}$, Ricardo Scholz ${ }^{b}$, Yunfei Xi ${ }^{a}$

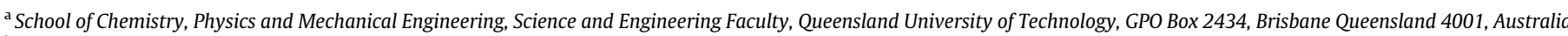 \\ ${ }^{\mathrm{b}}$ Geology Department, School of Mines, Federal University of Ouro Preto, Campus Morro do Cruzeiro, Ouro Preto, MG 35400-00, Brazil
}

\section{H I G H L I G H T S}

- We have studied the mineral ceruleite.

- The mineral ceruleite is an hydroxy arsenate of copper and aluminium of formula $\mathrm{Cu}_{2} \mathrm{Al}_{7}\left(\mathrm{AsO}_{4}\right)_{4}(\mathrm{OH})_{13} \cdot 11.5\left(\mathrm{H}_{2} \mathrm{O}\right)$.

- The molecular structure of ceruleite has been assessed using vibrational spectroscopy.

- Hydrogen bond distances were estimated.

\section{A R T I C L E I N F O}

\section{Article history:}

Received 14 May 2013

Received in revised form 23 July 2013

Accepted 31 July 2013

Available online 8 August 2013

\section{Keywords}

Ceruleite

Arsenate

Roselite

Raman spectroscopy

Infrared spectroscopy
G R A P H I C A L A B S T R A C T

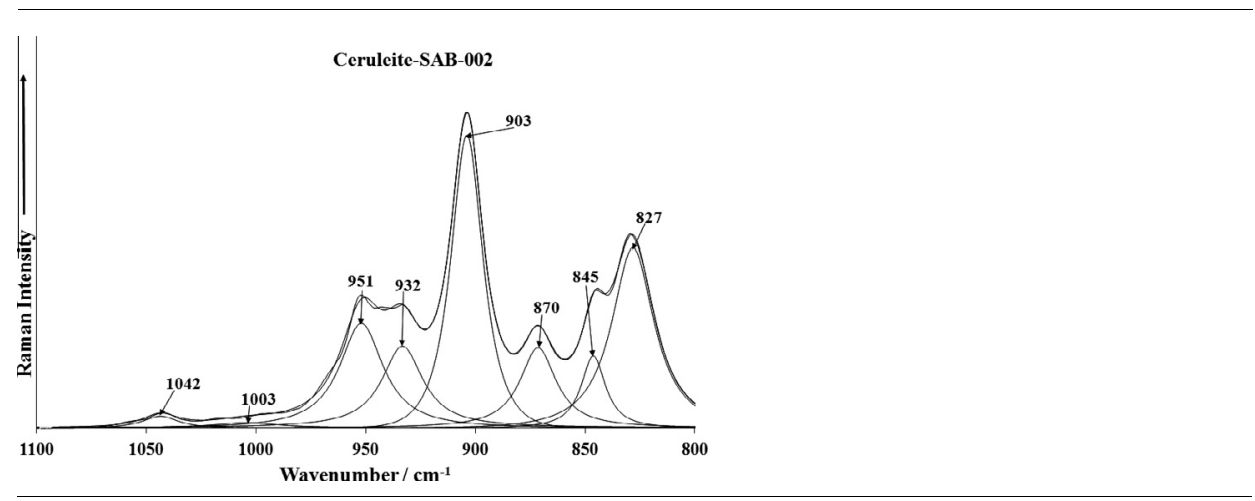

\begin{abstract}
A B S T R A C T
The molecular structure of the arsenate mineral ceruleite has been assessed using a combination of Raman and infrared spectroscopy. The most intense band observed at $903 \mathrm{~cm}^{-1}$ is assigned to the $\left(\mathrm{AsO}_{4}\right)^{3-}$ symmetric stretching vibrational mode. The infrared spectrum shows intense bands at 787 , 827 and $886 \mathrm{~cm}^{-1}$, ascribed to the triply degenerate $v_{3}$ antisymmetric stretching vibration. Raman bands observed at $373,400,417$ and $430 \mathrm{~cm}^{-1}$ are attributed to the $v_{2}$ vibrational mode. Three broad bands for ceruleite found at 3056, 3198 and $3384 \mathrm{~cm}^{-1}$ are assigned to water $\mathrm{OH}$ stretching bands. By using a Libowitzky empirical equation, hydrogen bond distances of 2.65 and $2.75 \AA$ are calculated. Vibrational spectra enable the molecular structure of the ceruleite mineral to be determined and whilst similarities exist in the spectral patterns with the roselite mineral group, sufficient differences exist to be able to determine the identification of the minerals.
\end{abstract}

(c) 2013 Elsevier B.V. All rights reserved.

\section{Introduction}

The mineral ceruleite is an hydroxy arsenate of copper and aluminium of formula $\mathrm{Cu}_{2} \mathrm{Al}_{7}\left(\mathrm{AsO}_{4}\right)_{4}(\mathrm{OH})_{13} \cdot 11.5\left(\mathrm{H}_{2} \mathrm{O}\right)[1-4]$. The mineral is found in the oxidized zone of arsenic-rich polymetallic mineral deposits and as a post-mine product [3-5]. The mineral appears to be sky-blue to a pale blue in colour. The mineral is triclinic with space group 1 bar [4,6,7]. The cell dimensions are

\footnotetext{
* Corresponding author. Tel.: +61 73138 2407; fax: +61 731381804 .

E-mail address: r.frost@qut.edu.au (R.L. Frost).
}

$a=14.359(3) \quad b=14.687(3) \quad c=7.440(1), \quad a=96.06(3)^{\circ} \quad(3=$ 93.19(4t $\left.\left.I=91.63(4)^{\circ} Z=2\right)\right)$. An infrared spectrum of ceruleite has been published [6]. This work has shown that the water is coordinated to the arsenate anion in the ceruleite structure.

The vibrational modes of oxyanions in aqueous systems are well known. The symmetric stretching vibration of the arsenate anion $\left(v_{1}\right)$ is observed at $810 \mathrm{~cm}^{-1}$ and coincides with the position of the antisymmetric stretching mode $\left(v_{3}\right)$. The symmetric bending mode $\left(v_{2}\right)$ is observed at $342 \mathrm{~cm}^{-1}$ and the antisymmetric bending mode $\left(v_{4}\right)$ at $398 \mathrm{~cm}^{-1}$. The positions of the arsenate vibrations occur at lower wavenumbers than any of the other naturally occurring oxyanions. Farmer lists a number of infrared spectra of 
arsenates including roselite, annabergite, erythrite, symplesite and köttigite [8]. The effect of reduced site symmetry in the crystal (compared with the free arsenate ion) will remove the degeneracy and allow splitting of the bands according to factor group analysis. Farmer based upon the work of Moenke reported the infrared spectra of roselite [8]. Farmer listed two bands at 985 and $920 \mathrm{~cm}^{-1}$ and assigned these bands to the $v_{1}\left(\mathrm{AsO}_{4}\right)^{2-}$ symmetric stretching vibrations [8]. The $v_{3}\left(\mathrm{AsO}_{4}\right)^{2-}$ symmetric stretching vibrations were listed as 870,850 and $805 \mathrm{~cm}^{-1}$. The assignment of these bands does not appear to correct. The $v_{4}$ bending modes were found at 453 and $435 \mathrm{~cm}^{-1}$. No $v_{2}$ bands were provided. A band at $535 \mathrm{~cm}^{-1}$ was not assigned but may well be attributed to a water libration mode. No $\mathrm{OH}$ stretching vibrations were tabled. For comparison Farmer listed the $v_{1}$ and $v_{3}$ bands of annabergite at $832 \mathrm{~cm}^{-1}$ and $795 \mathrm{~cm}^{-1}$. The $v_{4}$ bending modes were found at 510,460 and $427 \mathrm{~cm}^{-1}$ for annabergite. Two $\mathrm{OH}$ stretching vibrations were observed at 3430 and $3160 \mathrm{~cm}^{-1}$ for annabergite. A number of bands were listed which were unassigned. To the best of our knowledge, few Raman spectra of the fairfieldite and/or roselite mineral subgroups have been forthcoming [9].

Few comprehensive studies of the fairfieldite and roselite mineral subgroups and related minerals such as divalent cationic arsenates have been undertaken [8]. Most of the infrared data predates the advent of Fourier transform infrared spectroscopy [10-15]. Although some Raman studies of some arsenate minerals have been undertaken [16,17] no Raman spectroscopic investigation of roselite arsenate minerals has been forthcoming. Griffith did report the results of the Raman spectrum of a synthetic annabergite. The symmetric stretching mode of the $\left(\mathrm{AsO}_{4}\right)^{2-}$ unit was observed at $859 \mathrm{~cm}^{-1}$; the antisymmetric stretching mode at $880 \mathrm{~cm}^{-1}$, the symmetric bending mode at $438 \mathrm{~cm}^{-1}$ and antisymmetric bending mode at $452 \mathrm{~cm}^{-1}$; other bands were located at 797 and $820 \mathrm{~cm}^{-1}$ [18]. The structural investigation of some arsenates and the nature of the hydrogen bond in these structures have been undertaken. It was found that the hydroxyl unit was coordinated directly to the metal ion and formed hydrogen bonds to the arsenate anion [19].

As part of a comprehensive study of the molecular structure of minerals containing oxyanions such as the arsenate anion using of the IR and Raman spectroscopy, we report the vibrational spectroscopic properties of the above named ceruleite and relate the spectra to the structure of the mineral. A comparison is made with other arsenate bearing minerals.

\section{Experimental}

\section{Samples description and preparation}

The ceruleite sample studied in this work was collected from Emma Louisa gold mine, Guanaco district, about 100 km east-northeast of Taltal, Antofagasta, Chile. The mineral occurs in the oxidized zone of arsenic-rich polymetallic mineral deposits and as a post mining product. The sample was incorporated into the collection of the Geology Department of the Federal University of Ouro Preto, Minas Gerais, Brazil, with sample code SAB-002. The sample was gently crushed and the associated minerals were removed under a stereomicroscope Leica MZ4. Scanning electron microscopy (SEM) was applied to support the chemical characterization.

The Guanaco district is well known as an important source of arsenates. The region is the type locality of a number of minerals, including ceruleite.

\section{Scanning electron microscopy (SEM)}

Experiments and analyses involving electron microscopy were performed in the Center of Microscopy of the Universidade Federal de Minas Gerais, Belo Horizonte, Minas Gerais, Brazil (http:// www.microscopia.ufmg.br).

Ceruleite crystal aggregate was coated with a $5 \mathrm{~nm}$ layer of evaporated Au. Secondary Electron and Backscattering Electron images were obtained using a JEOL JSM-6360LV equipment. Qualitative and semi-quantitative chemical analysis in the EDS mode were performed with a ThermoNORAN spectrometer model Quest and was applied to support the mineral characterization.

\section{Raman microprobe spectroscopy}

Crystals of ceruleite were placed on a polished metal surface on the stage of an Olympus BHSM microscope, which is equipped with $10 \times, 20 \times$, and $50 \times$ objectives. The microscope is part of a Renishaw 1000 Raman microscope system, which also includes a monochromator, a filter system and a CCD detector (1024 pixels). The Raman spectra were excited by a Spectra-Physics model 127 He-Ne laser producing highly polarized light at $633 \mathrm{~nm}$ and collected at a nominal resolution of $2 \mathrm{~cm}^{-1}$ and a precision of $\pm 1 \mathrm{~cm}^{-1}$ in the range between 200 and $4000 \mathrm{~cm}^{-1}$. Repeated acquisitions on the crystals using the highest magnification $(50 \times)$ were accumulated to improve the signal to noise ratio of the spectra. Raman Spectra were calibrated using the $520.5 \mathrm{~cm}^{-1}$ line of a silicon wafer. The Raman spectrum of at least 10 crystals was collected to ensure the consistency of the spectra.

A Raman spectrum of ceruleite is given in the RRUFF data base and this spectrum with the marked peak positions is given in the Supplementary information as Fig. S1.

\section{Infrared spectroscopy}

Infrared spectra were obtained using a Nicolet Nexus 870 FTIR spectrometer with a smart endurance single bounce diamond ATR cell. Spectra over the $4,000,525 \mathrm{~cm}^{-1}$ range were obtained by the co-addition of 128 scans with a resolution of $4 \mathrm{~cm}^{-1}$ and a mirror velocity of $0.6329 \mathrm{~cm} / \mathrm{s}$. Spectra were co-added to improve the signal to noise ratio. The infrared spectra are given in the Supplementary information.

Spectral manipulation such as baseline correction/adjustment and smoothing were performed using the Spectracalc software package GRAMS (Galactic Industries Corporation, NH, USA). Band component analysis was undertaken using the Jandel 'Peakfit' software package that enabled the type of fitting function to be selected and allows specific parameters to be fixed or varied accordingly. Band fitting was done using a Lorentzia-Gaussian cross-product function with the minimum number of component bands used for the fitting process. The Gaussian-Lorentzian ratio was maintained at values greater than 0.7 and fitting was undertaken until reproducible results were obtained with squared correlations of $r^{2}$ greater than 0.995 .

\section{Results and discussion}

\section{Vibrational spectroscopy background}

According to Myneni et al. [20,21] and Nakamoto [22], $\left(\mathrm{AsO}_{4}\right)^{3-}$ is a tetrahedral unit, which exhibits four fundamental vibrations: the Raman active $v_{1}$ symmetric stretching vibration $\left(A_{1}\right)$ at $818 \mathrm{~cm}^{-1}$; the Raman active doubly degenerate $v_{2}$ symmetric bending vibration $(E)$ observed at $350 \mathrm{~cm}^{-1}$, the infrared and Raman active triply degenerate $v_{3}$ antisymmetric stretching vibration $\left(F_{2}\right)$ found around $786 \mathrm{~cm}^{-1}$, and the infrared and Raman active triply degenerate $v_{4}$ bending vibration $\left(F_{2}\right)$ observed at $405 \mathrm{~cm}^{-1}$. Protonation, metal complexation, and/or adsorption on a mineral surface will cause the change in $\left(\mathrm{AsO}_{4}\right)^{3-}$ symmetry from $T_{\mathrm{d}}$ to 
lower symmetries, such as $C_{3 v}, C_{2 v}$ or even $C_{1}$. This loss of degeneracy causes splitting of degenerate vibrations of $\mathrm{AsO}_{4}^{3-}$ and the shifting of the As- $\mathrm{OH}$ stretching vibrations to different wavenumbers.

Such chemical interactions reduce $\mathrm{AsO}_{4}^{3-}$ tetrahedral symmetry, as mentioned above, to either $C_{3 v} / C_{3}$ (corner-sharing), $C_{2 v} / C_{2}$ (edge-sharing, bidentate binuclear), or $C_{1} / C_{s}$ (corner-sharing, edgesharing, bidentate binuclear, multidentate) $[20,21]$. In association with $\mathrm{AsO}_{4}^{3-}$ symmetry and coordination changes, the $A_{1}$ band may shift to different wavenumbers and the doubly degenerate $E$ and triply degenerate $F$ modes may give rise to several new $A_{1}, B_{1}$, and/or $E$ vibrations $[20,21]$. In the absence of symmetry deviations, $\mathrm{AsO}_{3-}$ $\mathrm{OH}^{2-}$ in $\mathrm{C}_{3 \mathrm{v}}$ symmetry exhibit the $v_{\mathrm{s}} \mathrm{As}-\mathrm{OH}$ and $v_{\mathrm{as}}$ and $v_{\mathrm{s}} \mathrm{AsO}_{3} \mathrm{OH}^{2-}$ vibrations together with corresponding the $\delta$ As-OH in-plane bending vibration, $\delta$ As-OH out-of-plane bending vibration, $v_{\mathrm{s}} \mathrm{AsO}_{3} \mathrm{OH}^{2-}$ stretching vibration and $\delta_{\text {as }}\left(\mathrm{AsO}_{3} \mathrm{OH}\right)^{2-}$ bending vibration [23-25]. Keller [23] assigned observed the following infrared bands in $\mathrm{Na}_{2}(-$ $\left.\mathrm{AsO}_{3} \mathrm{OH}\right) \cdot 7 \mathrm{H}_{2} \mathrm{O} 450$ and $360 \mathrm{~cm}^{-1}$ to the $\delta_{\text {as }}\left(v_{4}\right)\left(\mathrm{AsO}_{3} \mathrm{OH}\right)^{2-}$ bend $(E), 580 \mathrm{~cm}^{-1}$ to the $\delta$ As-OH out-of-plane bend, $715 \mathrm{~cm}^{-1}$ to the $v$ As-OH stretch $\left(A_{1}\right), 830 \mathrm{~cm}^{-1}$ to the $v_{\text {as }} \mathrm{AsO}_{3} \mathrm{OH}^{2-}$ stretch $(E)$, and $1165 \mathrm{~cm}^{-1}$ to the $\delta \mathrm{As}-\mathrm{OH}$ in plane bend. In the Raman spectrum of $\mathrm{Na}_{2}\left(\mathrm{AsO}_{3} \mathrm{OH}\right) \cdot 7 \mathrm{H}_{2} \mathrm{O}$, Vansant and Veken [24] attributed observed Raman bands to the following vibrations $55,94,116$ and $155 \mathrm{~cm}^{-1}$ to lattice modes, $210 \mathrm{~cm}^{-1}$ to $v(\mathrm{OH} \cdots \mathrm{O})$ stretch, $315 \mathrm{~cm}^{-1}$ to $\left(\mathrm{AsO}_{3-}\right.$ $\mathrm{OH})^{2-}$ rocking, $338 \mathrm{~cm}^{-1}$ to the $\delta_{\mathrm{s}}\left(\mathrm{AsO}_{3}\right)^{2-}$ bend, $381 \mathrm{~cm}^{-1}$ to the $\delta_{\text {as }}\left(\mathrm{AsO}_{3} \mathrm{OH}\right)^{2-}$ bend, $737 \mathrm{~cm}^{-1}$ to the $v_{\mathrm{s}}$ As-OH stretch $\left(A_{1}\right)$, $866 \mathrm{~cm}^{-1}$ to the $v_{\text {as }}\left(\mathrm{AsO}_{3} \mathrm{OH}\right)^{2-}$ stretch $(E)$.

\section{Vibrational spectroscopy}

The Raman spectrum of ceruleite in the $100-4000 \mathrm{~cm}^{-1}$ spectral region is displayed in Fig. 1a. This figure shows the position of the
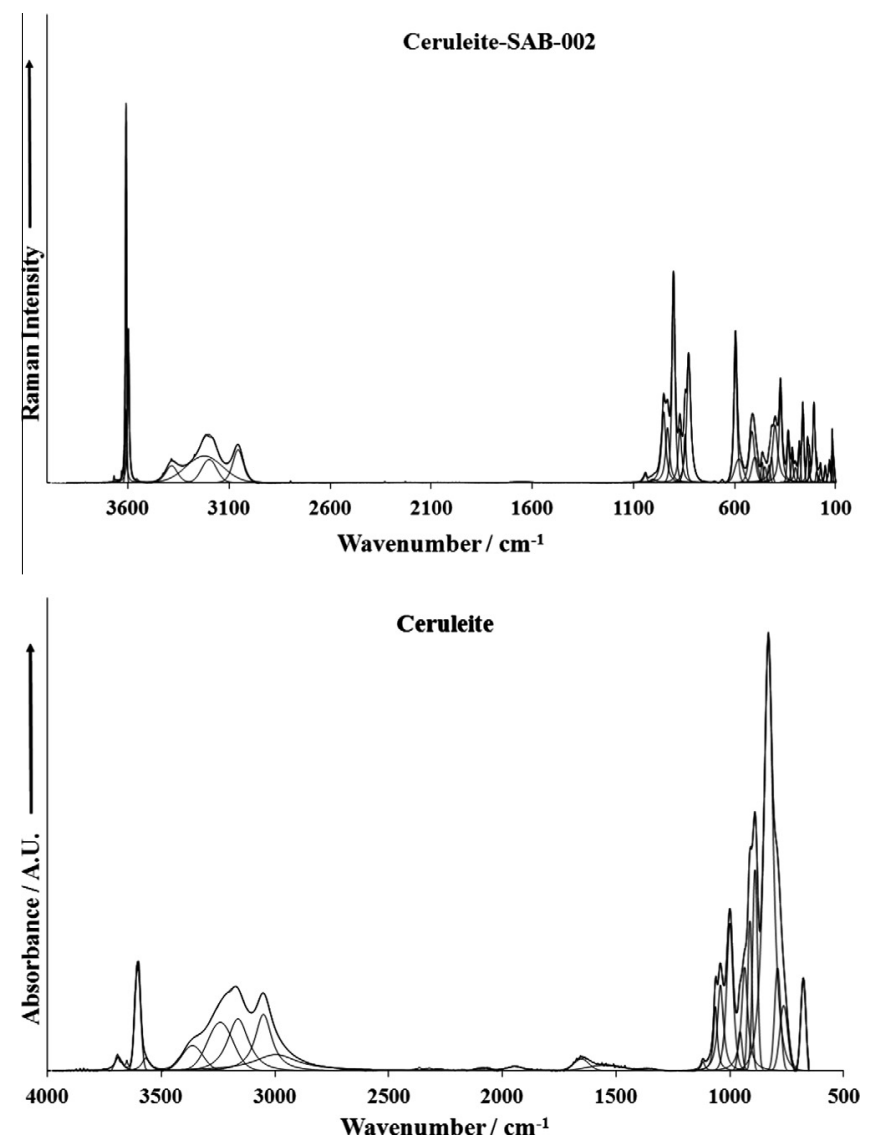

Fig. 1. (a) Raman spectrum of ceruleite over the $100-4000 \mathrm{~cm}^{-1}$ spectral range and (b) infrared spectrum of ceruleite over the $500-4000 \mathrm{~cm}^{-1}$ spectral range.
Raman bands and the relative intensity of these bands. It is observed that there are large parts of the spectrum where no intensity is found and therefore the spectrum is subdivided into sections based upon the type of vibration being examined. The infrared spectrum over the $500-4000 \mathrm{~cm}^{-1}$ spectral range is illustrated in Fig. 1b. This spectrum shows the position and relative intensities of the infrared bands. In a similar manner to the Raman spectrum, the infrared spectrum is subdivided into sections based upon the type of vibration being studied.

The Raman spectrum of ceruleite in the $800-1200 \mathrm{~cm}^{-1}$ spectral range is shown in Fig. 2a. The infrared spectrum of ceruleite in the $500-1300 \mathrm{~cm}^{-1}$ spectral range is shown in Fig. 2b. A Raman spectrum of ceruleite from the RRUFF data base is reported in Fig. S1. This figure shows the position and intensity of the peaks in the $100-1100 \mathrm{~cm}^{-1}$ spectral range. There is a strong similarity between the spectrum reported in this work and that on the RRUFF data base. The RRUFF spectrum does suffer from a lack of signal; and also the spectrum of the hydroxyl stretching region is not shown. The most intense band is observed at $903 \mathrm{~cm}^{-1}$ and is assigned to the $\left(\mathrm{AsO}_{4}\right)^{3-}$ symmetric stretching vibrational mode. The band is observed at $900 \mathrm{~cm}^{-1}$ for the RRUFF spectrum. According to Myneni et al. [20,21] and Nakamoto [22], $\left(\mathrm{AsO}_{4}\right)^{3-}$ is a tetrahedral unit, which exhibits four fundamental vibrations: the Raman active $v_{1}$ symmetric stretching vibration $\left(A_{1}\right)$ at $818 \mathrm{~cm}^{-1}$. Thus, the band at $903 \mathrm{~cm}^{-1}$ is shifted from the expected position. Protonation, metal complexation, and/or adsorption on a mineral surface will cause the change in $\left(\mathrm{AsO}_{4}\right)^{3-}$ symmetry from $T_{\mathrm{d}}$ to lower symmetries, such as $C_{3 v}, C_{2 v}$ or even $C_{1}$. This loss of degeneracy causes splitting of degenerate vibrations of $\mathrm{AsO}_{4}^{3-}$ and the shifting of the As- $\mathrm{OH}$ stretching vibrations to different wavenumbers. The Raman spectrum (Fig. 1a) displays three bands at 827,845
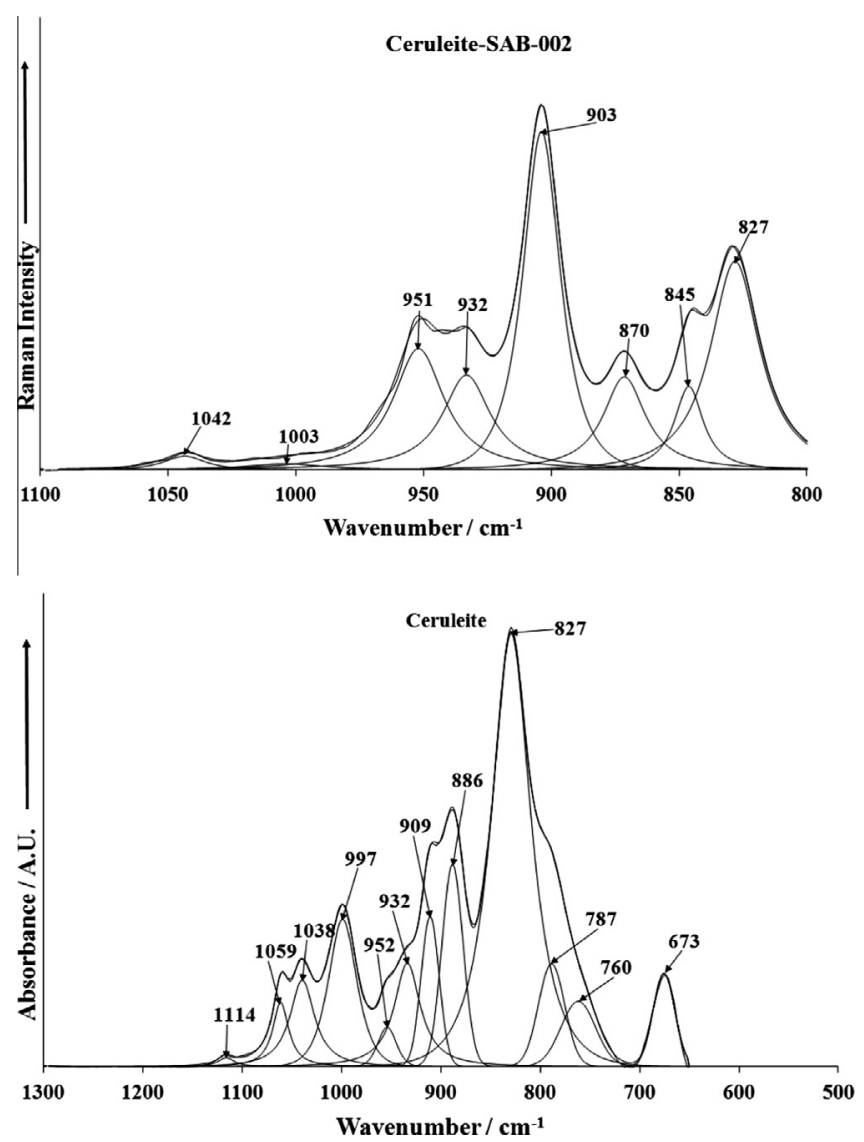

Fig. 2. (a) Raman spectrum of ceruleite over the $800-1400 \mathrm{~cm}^{-1}$ spectral range and (b) infrared spectrum of ceruleite over the $500-1300 \mathrm{~cm}^{-1}$ spectral range. 
and $870 \mathrm{~cm}^{-1}$. According to Myneni et al. [20,21] and Nakamoto [22], the infrared and Raman active triply degenerate $v_{3}$ antisymmetric stretching vibration $\left(F_{2}\right)$ should be found around $786 \mathrm{~cm}^{-1}$. Again, as for the symmetric stretching mode, the antisymmetric stretching vibrations are observed at higher wavenumbers than might be predicted. Two bands are observed in the RRUFF spectrum at 824 and $869 \mathrm{~cm}^{-1}$ and are attributed to this vibrational mode.

The position of $\mathrm{AsO}_{4}$ stretching bands appears to vary depending on the cation in the formula of the roselite subgroup mineral. Bands are observed for talmessite $\left(\mathrm{Ca}_{2} \mathrm{Mg}\right)$ at 828,814 and $781 \mathrm{~cm}^{-1}$. For the talmessite $\left(\mathrm{Ca}_{2} \mathrm{Co}\right)$ Raman bands are observed at 868,841 and $824 \mathrm{~cm}^{-1}$. For the mineral roselite two bands are observed at 864 and $798 \mathrm{~cm}^{-1}$. Raman bands have been observed at 854 and $800 \mathrm{~cm}^{-1}$ for annabergite. In the roselite subgroup, Raman spectra do not appear to be any phosphate isomorphic substitution. In the infrared spectra of roselite as reported by Farmer, two infrared bands were reported at 985 and $920 \mathrm{~cm}^{-1}$. These bands were assigned by Farmer to the $v_{1}$ symmetric stretching mode of the $\left(\mathrm{AsO}_{4}\right)^{3-}$ anion. Such an assignment in the light of these Raman results for roselite seems unlikely. A more likely assignment is to the $v_{1}$ symmetric stretching mode of the $\left(\mathrm{PO}_{4}\right)^{3-}$ anion. This isomorphic substitution of phosphate for arsenate may in itself be unusual as whilst cationic isomorphic substitution is common, it is not known whether the anionic substitution is common. Current literature does not report any anionic isomorphic substitution. Raman spectral studies of the vivianite phosphates show that there is a band at $951 \mathrm{~cm}^{-1}$ for vivianite and bobierrite. The bands are observed at 852 and $792 \mathrm{~cm}^{-1}$ for erythrite and at 875 and $807 \mathrm{~cm}^{-1}$ for hörnesite. No bands are ob-
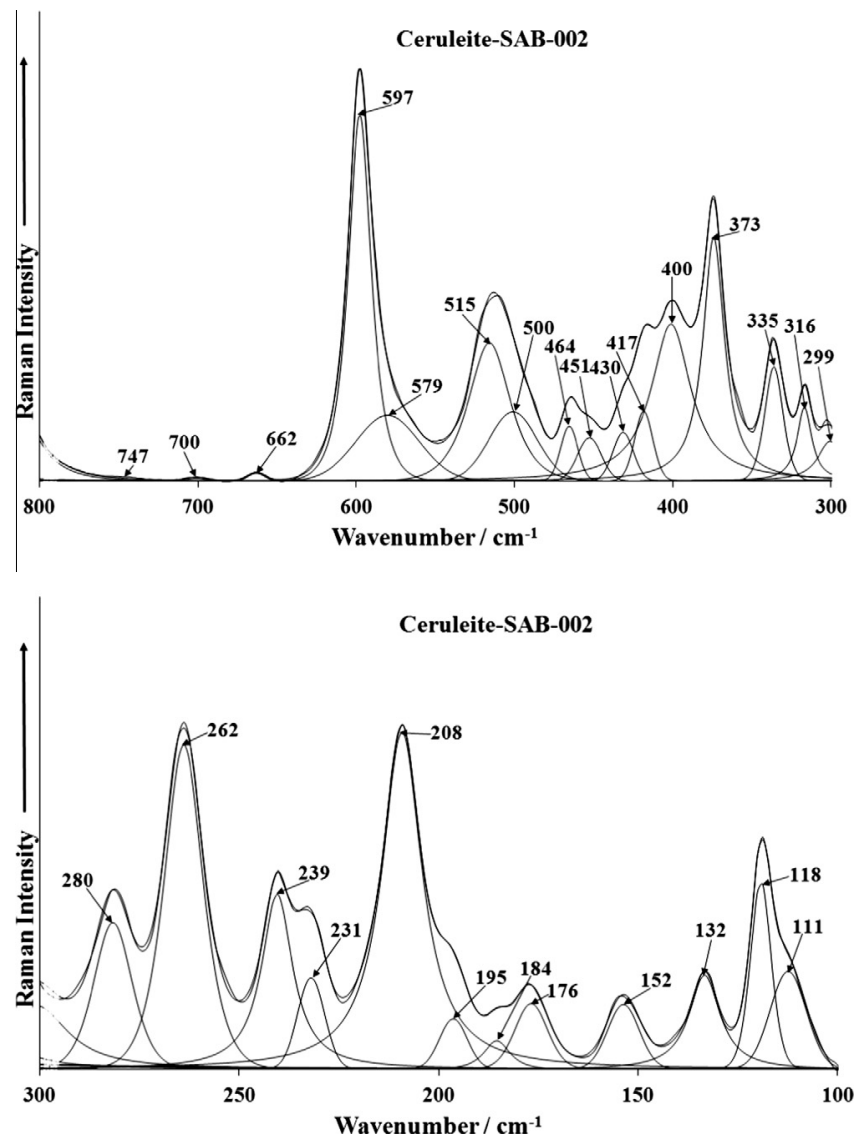

Fig. 3. (a) Raman spectrum of ceruleite over the $300-800 \mathrm{~cm}^{-1}$ spectral range and (b) Raman spectrum of ceruleite over the 100 to $300 \mathrm{~cm}^{-1}$ spectral range. served in these positions for the roselite minerals. Bands at 841 (talmessite-Co), $828 \mathrm{~cm}^{-1}$ (talmessite) $798 \mathrm{~cm}^{-1}$ (roselite are assigned to the $v_{1}$ symmetric stretching modes of $A_{1}$ symmetry. Griffith [26] reported Raman bands for a synthetic annabergite at 880 , 859,820 and $797 \mathrm{~cm}^{-1}$.

The infrared spectrum shows intense infrared bands at 787 , $827,886 \mathrm{~cm}^{-1}$. These bands are ascribed to the triply degenerate $v_{3}$ antisymmetric stretching vibration. The infrared band at $909 \mathrm{~cm}^{-1}$ is the equivalent of the Raman band at $903 \mathrm{~cm}^{-1}$ and is attributed to the $v_{1}$ symmetric stretching vibration. The fact that this band is observed in the infrared spectrum supports the concept that the symmetry of the arsenate anion is reduced to $C_{3 \mathrm{v}}$, $C_{2 v}$ or even $C_{1}$. The Raman peaks at 932,951 , and $1042 \mathrm{~cm}^{-1}$ are attributed to phosphate bands. This, perhaps, is not unexpected as phosphate can readily substitute for arsenate in isomorphic substitution. It is thought that phosphate bands are observed in the infrared spectrum at 997, 1038, 1059 and $1114 \mathrm{~cm}^{-1}$.

The Raman spectra of ceruleite in the $300-800 \mathrm{~cm}^{-1}$ and 100 $300 \mathrm{~cm}^{-1}$ spectral ranges are given in Fig. 3. The Raman active doubly degenerate $v_{2}$ symmetric bending vibration $(E)$ would be expected to be observed at $\sim 350 \mathrm{~cm}^{-1}$. Raman bands are observed at $373,400,417$ and $430 \mathrm{~cm}^{-1}$ and are attributed to this vibrational mode. In the RRUFF spectrum, Raman bands are observed at 373, 397 and $463 \mathrm{~cm}^{-1}$. The infrared and Raman active triply degenerate $v_{4}$ bending vibration $\left(F_{2}\right)$ is expected at around $405 \mathrm{~cm}^{-1}$. Strong Raman bands for ceruleite are found at 515 and $597 \mathrm{~cm}^{-1}$. In the RRUFF spectrum, the Raman bands are observed at 507 and $594 \mathrm{~cm}^{-1}$. The position of these bands seems high to be assigned to the $v_{4}$ bending modes. In association with $\mathrm{AsO}_{4}^{3-}$ symmetry and coordination changes, the triply degenerate $F$ modes may
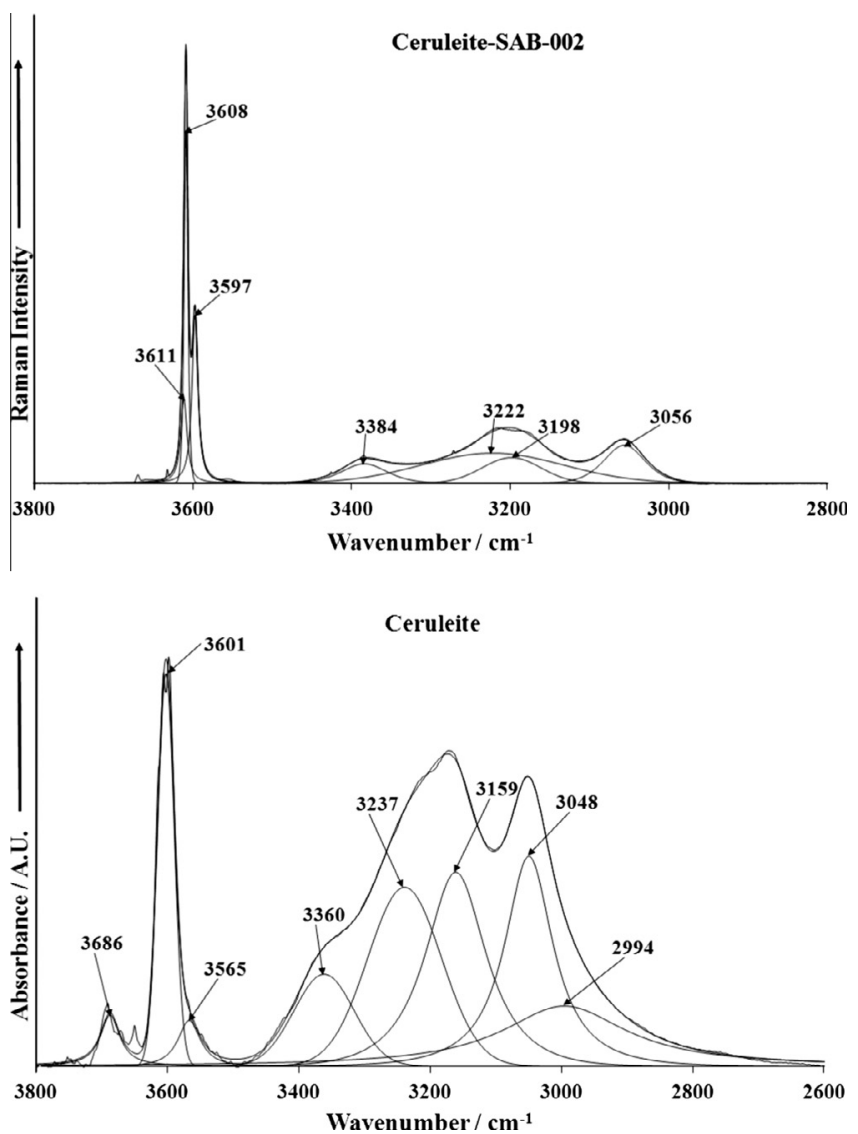

Fig. 4. (a) Raman spectrum of ceruleite over the $2600-4000 \mathrm{~cm}^{-1}$ spectral range and (b) infrared spectrum of ceruleite over the $2600-4000 \mathrm{~cm}^{-1}$ spectral range. 
give rise to several new $A_{1}, B_{1}$, and/or $E$ vibrations, which may occur at higher wavenumbers $[20,21]$. It is probable that the peaks in the $300 \mathrm{~cm}^{-1}$ region are due to metal oxygen stretching vibrations. Raman bands at 299, 316 and $335 \mathrm{~cm}^{-1}$ are observed. Quite intense Raman bands are found in the $100-300 \mathrm{~cm}^{-1}$ spectral range. Raman bands are found at 208 and $262 \mathrm{~cm}^{-1}$ with Raman bands of lesser intensity at 118, 132, 152, 176, 231, 239 and $280 \mathrm{~cm}^{-1}$. These bands are due to external vibrations and are simply referred to as lattice vibrations.

The Raman spectrum in the $2600-3800 \mathrm{~cm}^{-1}$ spectral range is illustrated in Fig. 4a. This spectral range is where the $\mathrm{OH}$ stretching vibrations are found. Two spectral features are observed. Firstly a series of low intensity Raman bands at 3056, 3198 and $3384 \mathrm{~cm}^{-1}$. These bands are attributed to water stretching vibrations. The second feature is the sharp Raman bands at 3597 and $3608 \mathrm{~cm}^{-1}$ with a shoulder band at $3611 \mathrm{~cm}^{-1}$. These bands are assigned to the stretching vibrations of the hydroxyl units. The observation of these multiple bands supports the concept of the nonequivalence of the $\mathrm{OH}$ units in the structure of ceruleite.

In contrast, strong infrared bands are observed at 3048, 3159, 3237 and $3360 \mathrm{~cm}^{-1}$ and are assigned to water stretching vibrations. These bands are ascribed to water stretching vibrations. An intense, somewhat broad band at $3601 \mathrm{~cm}^{-1}$ is assigned to the stretching vibrations of the hydroxyl units.

The Raman spectrum of ceruleite over the $1400-1800 \mathrm{~cm}^{-1}$ spectral range is given in Fig. 5a. The spectrum suffers from a lack of signal; nevertheless, a Raman band is identified at $1654 \mathrm{~cm}^{-1}$ which is attributed to the bending mode of water. The infrared spectrum over the $1300-1800 \mathrm{~cm}^{-1}$ spectral range is reported in Fig. $5 \mathrm{~b}$. The water bending mode is again observed at $1649 \mathrm{~cm}^{-1}$.
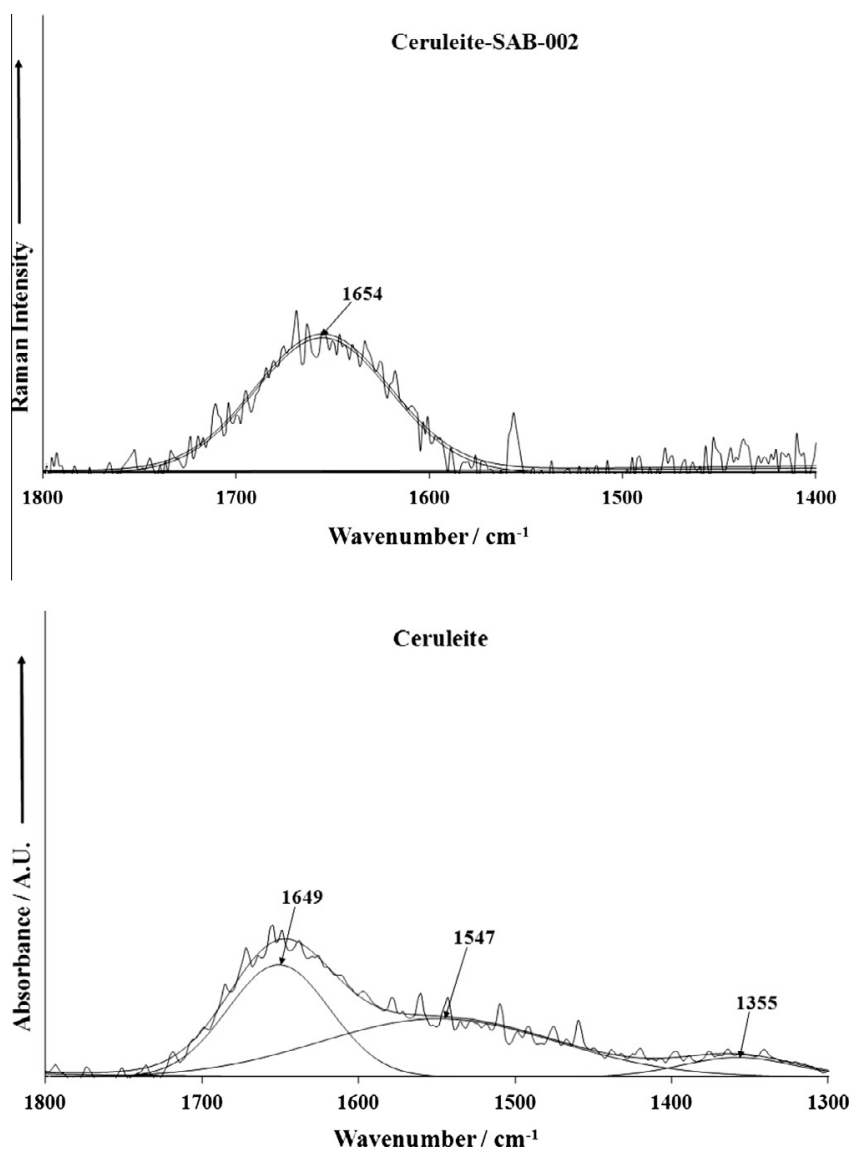

Fig. 5. (a) Raman spectrum of ceruleite over the $1300-1800 \mathrm{~cm}^{-1}$ spectral range and (b) infrared spectrum of ceruleite over the $1300-1800 \mathrm{~cm}^{-1}$ spectral range.
Studies have shown a strong correlation between $\mathrm{OH}$ stretching frequencies and both the $\mathrm{O} \ldots \mathrm{O}$ bond distances and with the $\mathrm{H} \cdots \mathrm{O}$ hydrogen bond distances [27-30]. The elegant work of Libowitzky (1999) showed that a regression function could be employed relating the above correlations with regression coefficients better than 0.96 [31]. The $\mathrm{OH}$ stretching vibrations in the infrared spectra of ceruleite, enable the calculation of predicted hydrogen bond distances of $2.6626 \AA\left(3056 \mathrm{~cm}^{-1}\right), 2.7092 \AA\left(3198 \mathrm{~cm}^{-1}\right) 2.7532 \AA$ $\left(3322 \mathrm{~cm}^{-1}\right)$. The values for the $\mathrm{OH}$ units are too high to be useful for the calculations using the Libowitzky formula. The meaning is that the hydrogen bond distances between the $\mathrm{OH}$ units and the arsenate anions are very long, thus indicating the hydrogen bonding is weak. In contrast, the hydrogen bond distances between the water molecules and the arsenate units is significantly shorter indicating the hydrogen bonding is strong.

A comparison may be made with the hydrogen bond distances of other arsenate minerals. Four hydrogen bond distances for talmessite are $2.76 \AA, 2.72 \AA, 2.71 \AA$ and $2.697 \AA$. For roselite, hydrogen bond distances of 2.75 and $2.67 \AA$ are calculated. Two types of water molecules are identified in the structure and the known hydrogen bond distances used to predict the hydroxyl stretching frequencies. The data fundamentally distinguishes between two types of water according to the hydrogen bond distances, namely strongly hydrogen bonded water and weakly hydrogen bonded water. However the predicted values do not take into account factor group splitting, accidental degeneracy and in-phase and out-ofphase vibrations. The strong hydrogen bonding would suggest that the thermal decomposition of the minerals would take place at significantly high temperatures. Some thermal studies were performed on collinsite, fairfieldite, and talmessite, and show the dehydration temperature increased with the strength of $\mathrm{H}$ bonds [32].

\section{Conclusions}

A combination of Raman spectroscopy at ambient temperatures complimented with infrared spectroscopy has been used to characterize the arsenate mineral known as ceruleite and also arsenates of the roselite mineral subgroup. The fundamental vibrations in the spectra are related to the structure of the minerals.

The ceruleite arsenate mineral is characterized by typical spectra of the $\mathrm{AsO}_{4}$ units. The symmetric stretching modes are observed in the $800-950 \mathrm{~cm}^{-1}$ region; the antisymmetric stretching modes are observed in the $827-870 \mathrm{~cm}^{-1}$ region. Some bands are observed around $950 \mathrm{~cm}^{-1}$ region and are attributed to water librational modes. The $v_{4}$ bending modes are observed around $500 \mathrm{~cm}^{-1}$ and the $v_{2}$ bending modes in the $373-430 \mathrm{~cm}^{-1}$ region. Multiple bands are observed in these regions indicating a loss of symmetry of the $\mathrm{AsO}_{4}$ unit. Intense sharp Raman bands at 3597 and $3608 \mathrm{~cm}^{-1}$ assigned to the stretching vibrations of the hydroxyl units. The observation of multiple bands offers credence to the non-equivalence of the $\mathrm{OH}$ units in the ceruleite structure. Vibrational spectroscopy enables aspects of the molecular structure of ceruleite to be evidenced.

\section{Acknowledgments}

The financial and infra-structure support of the Discipline of Nanotechnology and Molecular Science, Science and Engineering Faculty of the Queensland University of Technology, is gratefully acknowledged. The Australian Research Council (ARC) is thanked for funding the instrumentation. The authors would like to acknowledge the Center of Microscopy at the Universidade Federal de Minas Gerais (http://www.microscopia.ufmg.br) for providing the equipment and technical support for experiments involving 
electron microscopy. R. Scholz thanks to CNPq - Conselho Nacional de Desenvolvimento Científico e Tecnológico (Grant No. 306287/ 2012-9).

\section{Appendix A. Supplementary material}

Supplementary data associated with this article can be found, in the online version, at http://dx.doi.org/10.1016/j.saa.2013.07.103.

\section{References}

[1] H. Dufet, Bull. Soc. Franc. Min. 23 (1900) 147-150.

[2] S. Kihara, Y. Nakano, Hoseki Gakkaishi 6 (1979) 73-76.

[3] K. Schmetzer, H. Bank, W. Berdesinski, E. Krouzek, J. Gem. 16 (1978) 86-90.

[4] K. Schmetzer, W. Berdesinski, H. Bank, E. Krouzek, Neues Jahr. Min. (1976) 418-425.

[5] V. Ettler, M. Mihaljevic, O. Sebek, Waste Man. Res. 28 (2010) 587-595.

[6] R.S.W. Braithwaite, Min. Mag. 51 (1987) 738-741.

[7] J.S. Lee, J.O. Nriagu, Environ. Chem. 4 (2007) 123-133.

[8] V.C. Farmer, Mineralogical Society Monograph 4: The Infrared Spectra of Minerals, London, 1974.

[9] R.L. Frost, Spectrochim. Acta A71 (2008) 1788-1794.

[10] K. Omori, T. Seki, Ganseki Kobutsu Kosho Gakkaishi 44 (1960) 7-13.
[11] S.V. Gevork’yan, A.S. Povarennykh, Konst. Svoistva Miner. 7 (1973) 92-99.

[12] S.V. Gevork'yan, A.S. Povarennykh, Mineral. Zh. 2 (1980) 29-36.

[13] G.R. Hunt, J.W. Salisbury, C.J. Lenhoff, Mod. Geol. 3 (1972) 121-132.

[14] G.R. Hunt, Geophys. 42 (1977) 501-513.

[15] R. Sitzia, Rend. Sem. Fac. Sc. di Cagliari 36 (1966) 105-115.

[16] B. Piriou, J.F. Poullen, J. Raman Spectrosc. 15 (1984) 343-346.

[17] C.A. Melendres, N. Camillone III, T. Tipton, Electrochim. Acta 34 (1989) $281-$ 286.

[18] W.P. Griffith, J. Chem. Soc. A (1970) 286-291.

[19] V.I. Sumin De Portilla, Can. Min. 12 (1974) 262-268.

[20] S.C.B. Myneni, S.J. Traina, G.A. Waychunas, T.J. Logan, Geochim. Cosmochim. Acta 62 (1998) 3285-3300.

[21] S.C.B. Myneni, S.J. Traina, G.A. Waychunas, T.J. Logan, Geochim. Cosmochim. Acta 62 (1998) 3499-3514.

[22] K. Nakamoto, Infrared and Raman Spectra of Inorganic and Coordination Compounds, Wiley, New York, 1986.

[23] P. Keller, Neues Jb. Miner. Mh. (1971) 491-510.

[24] F.K. Vansant, B.J.V.D. Veken, J. Mol. Struct. 15 (1973) 439-444.

[25] F.K. Vansant, B.J.V.D. Veken, H.O. Desseyn, J. Mol. Struct. (1973) 425-437.

[26] W.P. Griffith, J. Chem. Soc. A (1970) 286-291.

[27] W. Mikenda, J. Mol. Struct. 147 (1986) 1-15.

[28] A. Novak, Struct. Bond. 18 (1974) 177-216.

[29] H. Lutz, Struct. Bond. 82 (1995) 85-103.

[30] J. Emsley, Chem. Soc. Rev. 9 (1980) 91-124.

[31] E. Libowitsky, Monat. Chem. 130 (1999) 1047-1049.

[32] M. Catti, G. Ferraris, G. Ivaldi, Bull. Soc. Franc. Min. Crist. 100 (1977) 230-236. 